\title{
Correlation of Clinical Findings with Radiological and Intraoperative Findings in Cases of Intestinal Obstruction
}

\author{
Sameer Pundeer ${ }^{1}$, Hardik Brahmbhatt ${ }^{2}$, Sharadendu Bali ${ }^{3}$, Tejinder Pal Singh Sodhi ${ }^{4}$, Kirti Savyasachi Goyal ${ }^{5}$ \\ ${ }^{1}$ Department of General Surgery, MMIMSR, MM-Deemed to be University, Mullana, Ambala, Haryana, India. \\ ${ }^{2}$ Department of General Surgery, MMIMSR, MM-Deemed to be University, Mullana, Ambala, Haryana, India. \\ ${ }^{3}$ Department of General Surgery, MMIMSR, MM-Deemed to be University, Mullana, Ambala, Haryana, India. \\ ${ }^{4}$ Department of General Surgery, MMIMSR, MM-Deemed to be University, Mullana, Ambala, Haryana, India. \\ ${ }^{5}$ Department of General Surgery, MMIMSR, MM-Deemed to be University, Mullana, Ambala, Haryana, India.
}

\section{ABSTRACT}

\section{BACKGROUND}

Intestinal obstruction accounts for $15 \%$ of all patients presenting to emergency department with complaints of acute abdominal pain. Recognising obstruction early, aggressive preoperative treatment, skilled surgical techniques and intensive postoperative management improves outcome. We wanted to correlate the clinical findings with radiological and intra-operative findings in cases of intestinal obstruction.

\section{METHODS}

50 cases of intestinal obstruction chosen by simple random technique, were studied in the department of general surgery at MMIMSR, Mullana, Ambala. Intraoperative findings were compared with x-ray, USG abdomen and CT abdomen findings.

\section{RESULTS}

Adhesions and bands (26\%) were found to be the most common cause of intestinal obstruction. Most common finding on plain x-ray abdomen was the presence of dilated gut loops (82\%). USG abdomen has limited diagnostic value in cases of intestinal obstruction with most common finding reported in USG abdomen being that of small bowel obstruction (62\%). Out of 49 patients who underwent CT scan abdomen and surgery, CT findings matched with intraoperative in 45 patients (91.84\%) and the most common finding was adhesions and bands (22.4\%).

\section{CONCLUSIONS}

X-ray abdomen and USG abdomen have limitations and are diagnostic only in a handful of cases. CT abdomen provides much more elaborate information and helps the surgeon to understand the pathology. Preoperative CT also helps prevent laparotomies in scenarios where surgeon with preoperative knowledge can opt for laparoscopic approach, thereby reducing postoperative stay in the hospital and complication. So, understanding of the imaging modalities and knowing when to use them and what to look for can save precious time of the patient and also that of the surgeon allowing for early diagnosis and better plan of treatment.

\section{KEY WORDS}

Intestinal Obstruction, Adhesions, Intraop and Radiological Correlation
Corresponding Author:

Dr. Sameer Pundeer,

Hostel 9, MM (Deemed to be University),

Campus, Mullana-133207, Ambala,

Haryana, India.

E-mail: samimpact@yahoo.com

DOI: $10.14260 / \mathrm{jemds} / 2020 / 160$

Financial or Other Competing Interests: None.

How to Cite This Article:

Pundeer S, Brahmbhatt H, Bali S, et al. Correlation of clinical findings with radiological and intraoperative findings in cases of intestinal obstruction. J. Evolution Med. Dent. Sci. 2020;9(10):736-740, DOI: 10.14260/jemds/2020/160

Submission 03-01-2020,

Peer Review 15-02-2020,

Acceptance 22-02-2020,

Published 09-03-2020. 


\section{BACKGROUND}

Intestinal obstruction accounts for $15 \%$ of all patients presenting to emergency department with complaints of acute abdominal pain. Its manifestation ranges from mild abdominal discomfort and abdominal distension to hypovolemia or septic shock. The mortality rate ranges from $3 \%$ in simple obstruction to $30 \%$ when there is vascular compromise or perforation of bowel. This is further influenced by the clinical setting and related comorbidities. ${ }^{1,2}$ Due to early detection of underlying causes, improved surgical techniques and intensive postoperative care, results are gratifying than ever. Intestinal obstruction may occur due to varying causes, most common being adhesions, neoplasms and herniation. $60 \%$ of reported intestinal obstruction cases result from prior abdominal surgeries. $^{3}$ less common causes of obstruction are intussusceptions, gall bladder calculi, foreign body, volvulus and intra-abdominal abscess.

An upright abdominal radiograph is a must to rule out intestinal perforation which is seen as free air under the right dome of diaphragm. Radiography accurately diagnoses IO in approximately $60 \%$ of cases ${ }^{4}$ and its positive predictive value approaches $80 \%$ in patients with high grade I0.5 Ultrasound abdomen is a preliminary investigation in patients with abdominal pain and distension and has high sensitivity for high grade obstruction, approaching $85 \% .^{6}$ If on clinical examination and radiography, a definite diagnosis cannot be established; CT would be appropriate for further evaluation. CT is a highly sensitive investigation to detect high grade intestinal obstruction and also has benefits in defining the aetiology and level of obstruction. . $^{70}$

Treatment of intestinal obstruction includes correction of physiological derangements, bowel rest and removing the cause of obstruction. Dehydration is corrected with resuscitation using IV fluids. Antibiotics are administered to prevent regrowth and translocation of bacteria across bowel wall.11 Antibiotic coverage must include gram negative and anaerobic bacteria. Replacement of electrolytes following a check on renal function test is a must. Recognising obstruction, early diagnosis, aggressive preoperative treatment, skilled surgical techniques and intensive postoperative management improves outcome.

We wanted to correlate clinical findings with radiological and operative findings in cases of intestinal obstruction.

\section{METHODS}

The study was conducted in the Department of General Surgery, MMIMISR, Mullana, Ambala. It was approved by the IEC with no. IEC-1082. This was a prospective study of patients $>18$ years of age who presented to our department with the symptoms of Intestinal Obstruction. 50 patients fulfilling the inclusion criteria of this study were studied after taking informed consent from the patients. All adults admitted to Department of General Surgery with features of intestinal obstruction who underwent exploratory laparotomy were included in the study.

\section{Exclusion Criteria}

- All patients below the age of 18 years

- pregnant female patients

- All patients with obstruction which resulted in perforation

Parameters which were recorded in every admitted case of intestinal obstruction were detailed history and clinical examination, relevant laboratory and radiological investigations of the patients, operative findings, etiology of obstruction and the surgical procedure employed. After completion of the study results were tabulated and data studied.

\section{RESULTS}

\begin{tabular}{|c|c|c|}
\hline & No. of Cases & Percentage \\
\hline Normal & 3 & 6 \\
\hline MAFL & 23 & 46 \\
\hline DL & 41 & 82 \\
\hline \multicolumn{2}{|c|}{ Table 1. Distribution of Cases on the Basis of X-ray Abdomen } \\
Erect Findings \\
\hline
\end{tabular}

Table 1 shows distribution of cases on the basis of X-ray abdomen erect findings. 3 patients of intestinal obstruction had normal x-ray findings. Most common finding was dilated gut loops seen in 41 patients. Dilatation of small gut more than $\mathrm{cm}$ and more than $6 \mathrm{cms}$ for large intestine was taken significant. Other finding taken into account was presence of air-fluid levels with more than 3 as significant. It was seen in 23 patients in our study.

\begin{tabular}{|c|c|c|}
\hline Findings & No. of Cases & Percentage \\
\hline Normal & 4 & 8 \\
\hline SAIO & 5 & 10 \\
\hline SBO & 31 & 62 \\
\hline LBO & 2 & 4 \\
\hline OIH & 1 & 2 \\
\hline Intussusception & 3 & 6 \\
\hline Carcinoma & 3 & 6 \\
\hline Meckel's diverticulum & 1 & 2 \\
\hline Total & $\mathbf{5 0}$ & $\mathbf{1 0 0}$ \\
\hline \multicolumn{2}{|c|}{} \\
Table 2. Distribution of Cases on the Basis of USG Abdomen Findings \\
\hline
\end{tabular}

Table 2 shows distribution of cases on the basis of USG abdomen findings. Most common finding reported was Small bowel obstruction in 31 patients. Least common findings reported were obstructed inguinal hernia and Meckel's diverticulum each being 1 case.

\begin{tabular}{|c|c|c|}
\hline & No. of Cases & Percentage \\
\hline Mesenteric ischaemia & 10 & 20.4 \\
\hline Adhesions & 6 & 12.2 \\
\hline Bands & 5 & 10.2 \\
\hline Stricture & 9 & 18.36 \\
\hline Carcinoma & 7 & 14.28 \\
\hline Meckel's diverticulum & 2 & 4.08 \\
\hline Intussusception & 4 & 8.16 \\
\hline Koch's abdomen & 5 & 10.2 \\
\hline Bowel Malrotation & 1 & 2.04 \\
\hline Total & $\mathbf{4 9}$ & $\mathbf{1 0 0}$ \\
\hline Table 3. Distribution of Cases on the Basis of CT Abdomen Findings \\
\hline
\end{tabular}

Table 3 shows distribution of cases on the basis of CT abdomen findings. It was performed in 49 patients, 1 patient where it was not done was that of obstructed inguinal hernia. Most common cause of obstruction reported in CT abdomen were adhesions and bands together constituting 22.4\%, Mesenteric ischaemia (20.4\%). Least common cause of 
obstruction reported in CT abdomen was Bowel malrotation with 1 case.

\begin{tabular}{|c|c|c|}
\hline & No. of Cases & Percentage \\
\hline Gangrene bowel & 9 & 18 \\
\hline Adhesions & 6 & 12 \\
\hline Bands & 7 & 14 \\
\hline Stricture & 6 & 12 \\
\hline Carcinoma & 7 & 14 \\
\hline Meckel's diverticulum & 2 & 4 \\
\hline Intussusception & 4 & 8 \\
\hline Cocoon abdomen & 5 & 10 \\
\hline Bowel malrotation & 1 & 2 \\
\hline Mesenteric L. & 2 & 4 \\
\hline OIH & 1 & 2 \\
\hline Total & $\mathbf{5 0}$ & $\mathbf{1 0 0}$ \\
\hline Table 4. Distribution of Cases on the Basis of Intra-Operative Findings \\
\hline \multicolumn{2}{|c}{}
\end{tabular}

Table 4 shows distribution of cases on the basis of intra operative findings. Most common finding intra operatively was adhesions and bands seen in 13 cases, gangrenous bowel ( 9 cases). Least common finding seen intra operatively was that of obstructed inguinal hernia and bowel malrotation with one case each.

\section{DISCUSSION}

Intestinal obstruction till date remains one of the most common global surgical problem. Therefore, intestinal obstruction has earned great attention for further research. Brewer et al analysed 1000 consecutive abdominal surgeries in 1976 and reported an incidence of $2.5 \% .^{12}$ Jain et al in 1973 reported an incidence of $3.2 \% \cdot{ }^{13}$

\section{Aetiology}

The aetiology of IO is highly variable from our country to other and also from one state to other in the same country. In our study we found that $22 \%$ cases to be having adhesive IO due to adhesions or bands, followed by mesenteric ischemia (20\%) and strictures (18\%) (table 4).

\begin{tabular}{|c|c|c|c|c|c|c|c|c|}
\hline Cause & 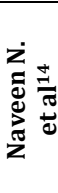 & 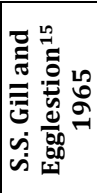 & 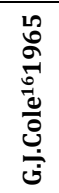 & 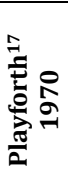 & 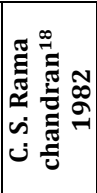 & 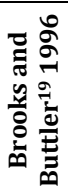 & 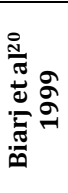 & 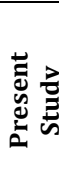 \\
\hline Adhesion & $42 \%$ & $15 \%$ & $15 \%$ & $10 \%$ & $23 \%$ & $23 \%$ & $53 \%$ & $26 \%$ \\
\hline Hernia & $20 \%$ & $27 \%$ & $27 \%$ & $35 \%$ & $13.6 \%$ & $25 \%$ & $26 \%$ & $2 \%$ \\
\hline \begin{tabular}{|l|} 
Intussusception \\
\end{tabular} & - & $12 \%$ & $12 \%$ & $12 \%$ & $7.4 \%$ & $18 \%$ & - & $8 \%$ \\
\hline Tuberculosis & $14 \%$ & $3.5 \%$ & $3.5 \%$ & $3 \%$ & $8.6 \%$ & - & - & $10 \%$ \\
\hline Malignancy & $16 \%$ & $3.4 \%$ & $3.4 \%$ & $4 \%$ & $9.3 \%$ & $5 \%$ & - & $14 \%$ \\
\hline Volvulus & $8 \%$ & $3.4 \%$ & $25 \%$ & $4 \%$ & $26.6 \%$ & $1 \%$ & $3 \%$ & - \\
\hline $\begin{array}{l}\text { Mesenteric } \\
\text { Ischaemia }\end{array}$ & - & - & - & - & - & - & $26 \%$ & $18 \%$ \\
\hline Stricture & - & - & - & - & - & - & - & $12 \%$ \\
\hline $\begin{array}{c}\text { Meckel's } \\
\text { diverticulum }\end{array}$ & - & - & - & - & - & - & - & $4 \%$ \\
\hline Bowel malrotation & - & - & - & - & - & - & - & $2 \%$ \\
\hline \multicolumn{9}{|c|}{$\begin{array}{c}\text { Table 5. Comparison of Aetiology of Intestinal Obstruction } \\
\text { in Different Studies }\end{array}$} \\
\hline
\end{tabular}

It has been noticed that the incidence of malignancies of the gut as the cause of intestinal obstruction was also quite high in our study (14\%) while obstruction due to abdominal tuberculosis was found in 5 cases $(10 \%)$.Two cases of Meckel's diverticulitis (4\%), Lipomatous polyp leading to intussusception (8\%) and one case of IO due to bowel malrotation $(1 \%)$ were found. When compared with few similar studies the incidence of TB and Typhoid were far less. Adhesions was commonest cause in all other studies including ours. On review of earlier Indian studies, $10 \%$ of IO were related to adhesions and recent studies revealed the incidence of adhesions gradually increasing to 23\% in 1982 to more than $30 \%$ in present study. In western studies, adhesive IO ranged from $40-60 \%$.

\section{Imaging}

X-Ray- In the present study $82 \%$ of X-ray shows multiple air fluid levels and $46 \%$ with dilated bowel loops. Taneja et al. report shows $90 \%$ of cases with multiple air fluid level and Savage et al. reports $95 \%$ cases with significant findings. Tiwari SJ et al. ${ }^{21}$ reported multiple air fluid levels in $70 \%$ patients. Suri et al. ${ }^{22}$ reported $77 \%$ sensitivity and $50 \%$ specificity of $x$-ray in the diagnosis of intestinal obstruction.

Ultrasonography- In present study, USG abdomen was suggestive of small bowel obstruction in $64 \%$ patients and normal in $8 \%$ patients. There were three patients each with USG abdomen suggestive of intussusception and carcinoma of the colon. Ogata et al. and associates reported that an akinetic, dilated loop of bowel observed on real-time USG has a high sensitivity (90\%) and specificity (93\%) for the recognition of strangulation; the positive predictive value was $73 \%$. Suri et al. ${ }^{22}$ reported $83 \%$ sensitivity and $100 \%$ specificity of USG abdomen in the diagnosis of intestinal obstruction. Venkanna et al. ${ }^{23}$ reported positive finding in $40 \%$ patients.

CT Scan Abdomen- In the present study 49 patients underwent CT scan and also underwent surgery. One patient who was not taken up for CT was that of obstructed inguinal hernia for whom USG was done and was taken up for surgery immediately. Sheedy et $\mathrm{al}^{24}$ noted that with CT, sensitivity was $15 \%$ and specificity $94 \%$ for identifying bowel ischaemia prospectively in patients with small bowel obstruction. Jancelewicz et $\mathrm{al}^{25}$ found that decreased bowel wall enhancement on CT, leucocytosis, and peritoneal signs were the only independent predictors of strangulation obstruction on a multiple logistic regression analysis. Tiwari SJ et al. ${ }^{21}$ reported multiple air fluid levels in $70 \%$ patients. Suri et al..$^{22}$ reported $93 \%$ sensitivity and $100 \%$ specificity of CT-scan in the diagnosis of intestinal obstruction.

\section{Correlation of CT Scan Findings with Intraoperative Findings in Cases of Intestinal Obstruction}

CT scan was done in 49 patients and it diagnosed all the cases correctly. One case left out was that of obstructed inguinal hernia. In majority of patients (91.84\%) CT findings matched with intraoperative findings whereas in $8.16 \%$ patients, CT findings did not match with intraoperative findings. In our study, the sensitivity of CT in revealing the cause of bowel obstruction was $100 \%$ and its specificity was $94.45 \%$. Saini DK et $\mathrm{al}^{26}$, performed a single centre prospective follow up study.18 Out of 40, 30 patients underwent exploratory laparotomy and it was found that MDCT was $85 \%$ sensitive and $70 \%$ specific in diagnosing bowel obstruction. Association between MDCT findings suggestive of obstruction and intra-operative findings turn out to be significant $(\mathrm{P}=0.003)$. MDCT findings were consistent with intraoperative findings in 22 out of 30 patients (73\%). In a study done by Vaishnani BV et al. ${ }^{27}$ CT had the sensitivity of 
91.48\%, Specificity 33.33\%, PPV 95.55\%, NPV 20\%. Similar results were obtained by Mallo RD et $\mathrm{al}^{28}$ who conducted a systemic review. This review was designed to describe the diagnostic performance of computed tomography (CT) in assessing bowel ischemia and complete obstruction in small bowel obstruction (SBO).

The increased use of Sonography in initial assessment of patients with abdominal pain has made point-of-care ultrasound a valuable tool for diagnosis of IO. Sonography is a sensitive but more specific than abdominal X-ray in diagnosis of I0.29,30 Furthermore it may detect the cause of obstruction and its level. ${ }^{31}$ Repeated scanning is safe and can be used to determine the progress of IO. Point-of-care ultrasound may detect bowel wall necrosis and evaluate the physiological status that can guide the resuscitation of patients with IO. ${ }^{32}$

IO still remains a common and important surgical emergency. Obstruction because of adhesions is one of the major causes and the incidence is increasing due to increased abdominal and pelvic surgeries. Obstruction due to external hernias is decreasing probably due to early elective open and laparoscopic surgeries. The morbidity and mortality depend upon the age of patients, delayed presentation, etiology, and site of obstruction, state of hydration, viability of bowel, delay in diagnosis, surgical intervention and associated medical illness.

Adhesions and bands (26\%) are the most common cause of intestinal obstruction found intraoperatively. Most common finding on plain $\mathrm{x}$-ray abdomen is the presence of dilated gut loops (82\%) followed by multiple air-fluid levels (46\%). USG abdomen has limited diagnostic value in cases of intestinal obstruction. The most common finding reported in USG abdomen was that of small bowel obstruction (62\%) and the least common being Meckel's diverticulum (2\%) and obstructed inguinal hernia (2\%). Out of 49 patients who underwent CT scan abdomen and surgery, CT findings matched with intraoperative in 45 patients $(91.84 \%)$ and the most common reported finding was adhesions and bands (22.4\%). In our study, the sensitivity of CT in revealing the cause of bowel obstruction was $100 \%$ and its specificity was $94.45 \%$.

\section{CONCLUSIONS}

CT abdomen is a valuable imaging modality in the diagnosis intestinal obstruction. Early recognition and aggressive treatment may help in preventing irreversible ischemia and transmural necrosis along with decreasing the morbidity and mortality. X-ray abdomen and USG abdomen have limitations and are diagnostic only in a handful of cases. CT abdomen provides much more elaborate information and helps the surgeon to understand the pathology. Preoperative CT also helps prevent laparotomies in scenarios where surgeon with preoperative knowledge can now opt for laparoscopic approach, thereby reducing postoperative stay in the hospital and complications. So, understanding of the imaging modalities and knowing when to use them and what to look for can save precious time of the patient and of the surgeon allowing for early diagnosis and better plan of treatment.

\section{REFERENCES}

[1] Irvin TT. Abdominal pain: a surgical audit of 1190 emergency admissions. Br J Surg 1989;76(11):1121-5.

[2] Wright HK, O'Brien JJ, Tilson MD. Water absorption in experimental closed segment obstruction of the ileum in man. Am J Surg 1971;121(1):96-9.

[3] Shelton BK. Intestinal obstruction [published correction appears in AACN Clin Issues 2000;11(1):following table of contents]. AACN Clin Issues 1999;10(4):478-91.

[4] Maglinte DDT, Heitkamp DE, Howard TJ, et al. Current concepts in imaging of small bowel obstruction. Radiol Clin North Am 2003;41(2):263-83, vi.

[5] Lappas JC, Reyes BL, Maglinte DD. Abdominal radiography findings in small-bowel obstruction: relevance to triage for additional diagnostic imaging. AJR Am J Roentgenol 2001;176(1):167-74.

[6] Lim JH, Ko YT, Lee DH et al. Determining the site and causes of colonic obstruction with sonography. AJR Am J Roentgenol 1994;163(5):1113-7.

[7] Suri S, Gupta S, Sudhakar PJ, et al. Comparative evaluation of plain films, ultrasound and CT in the diagnosis of intestinal obstruction. Acta Radiol 1999;40(4):422-28.

[8] Furukawa A, Yamasaki M, Furuichi K, et al. Helical CT in the diagnosis of small bowel obstruction. Radiographics 2001;21(2):341-55.

[9] Gazelle GS, Goldberg MA, Wittenberg J, et al. Efficacy of CT in distinguishing small-bowel obstruction from other causes of small-bowel dilatation. AJR Am J Roentgenol 1994;162(1):43-7.

[10] Frager DH, Baer JW, Rothpearl A, et al. Distinction between postoperative ileus and mechanical smallbowel obstruction: value of CT compared with clinical and other radiographic findings. AJR Am J Roentgenol 1995;164(4):891-4.

[11] Sagar PM, MacFie J, Sedman P, et al. Intestinal obstruction promotes gut translocation of bacteria. Dis Colon Rectum 1995;38(6):640-4.

[12] Brewer BJ, Golden GT, Hitch DC, et al. Abdominal pain. Am J Surg 1976;131(2):219-23.

[13] Sufian S, Matsumoto T. Intestinal obstruction. Am J Surg 1975;130(1):9-14.

[14] Naveen N, Mukherjee A, Nataraj YS, et al. A clinical study of intestinal obstruction and its surgical management in rural population. Journal of Evolution of Medical and Dental Sciences 2013;2(21):3636-49.

[15] Gill SS, Eggleston FC. Acute intestinal obstruction. Arch Surg 1965;91:389-92.

[16] Cole GJ. A review of 436 cases of intestinal obstruction in Ibanan. Gut 1965;6(2):151-62.

[17] Playforth RH, Holloway JB, Griffen WO Jr. Mechanical small bowel obstruction and plea for the earlier surgical intervention. Ann Surg 1970;171(5):783-8.

[18] Ramachandran CS. Acute intestinal obstruction: 15 years of experience. IJS 1982: p. 672-9.

[19] Brooks VE, Butler A. Acute intestinal obstruction in Jamaica. Surg Gynaec Obstet 1996;122(2):261-4 
[20] Biarj T. Complications and death after surgical treatment of small bowel obstruction. Ann Surg 1999;231(4):297306.

[21] Tiwari SJ, Mulmule R, Bijwe VN. A clinical study of acute intestinal obstruction in adults-based on etiology, severity indicators and surgical outcome. Int J Res Med Sci 2017;5(8):3688-96.

[22] Suri S, Gupta S, Sudhakar PJ, et al. Comparative evaluation of plain films, ultrasound and CT in diagnosis of intestinal obstruction. Acta Radiol 1999;40(4):422-8.

[23] Venkanna M, Srinivas D, Sharada B. Clinical, diagnostic and operative correlation of acute abdomen. Int J Sci Stud 2018;6(2):138-43.

[24] Sheedy SP, Earnest F 4th, Fletcher JG, et al. CT of smallbowel ischemia associated with obstruction in emergency department patients: diagnostic performance evaluation. Radiology 2006;241(3):729-36.

[25] Jancelewicz T, Vu LT, Shawo AE, et al. Predicting strangulated small bowel obstruction: an old problem revisited. J Gastrointest Surg 2009;13(1):93-9.

[26] Saini DK, Chaudhary P, Durga CK. Role of multislice computed tomography in evaluation and management of intestinal obstruction. Clin Pract 2013;3(2):e20.
[27] Vaishnani BV, Dudhwala MFG. Clinical study on role of CECT abdomen in intestinal obstruction. Int J Res Med Sci 2019;7(4):967-71.

[28] Mallo RD, Salem R, Lalani T, et al. Computed tomography diagnosis of ischemia and complete obstruction in small bowel obstruction: a systematic review. J Gastro-intest Surg 2005;9(5):690-4.

[29] Richardson NG, Heriot AG, Kumar D, et al. Abdominal ultrasonography in the diagnosis of colonic cancer. $\mathrm{Br} \mathrm{J}$ Surg 1998;85(4):530-3.

[30] Ogata M, Mateer JR, Condon RE. Prospective evaluation of abdominal sonography for the diagnosis of bowel obstruction. Ann Surg 1996;223(3):237-41.

[31] Silva AC, Pimenta M, Guimarães LS. Small bowel obstruction: What to look for? Radiographics 2009;29(2):423-39.

[32] Grassi R, Romano S, D'Amario F, etal. The relevance of free fluid between intestinal loops detected by sonography in the clinical assessment of small bowel obstruction in adults. Eur J Radiol 2004;50(1):5-14. 